\title{
Histological and molecular classification of breast cancer: what do we know?
}

\author{
Renan Gomes do Nascimento* (1), Kaléu Mormino Otoni² (1)
}

\section{ABSTRACT}

Breast cancer is the neoplasm most diagnosed malignancy and the leading cause of mortality among women on a global scale. A profound increase in the understanding and clinical management of breast cancer has occurred over the past two decades, which has led to significant progress in prevention, early detection, and personalized breast cancer therapy. However, the biggest obstacle still faced in clinical practice is the complete understanding of intertumoral and intratumoral heterogeneity, in addition to the mechanisms of multiple drug resistance in the systemic treatment of the disease. In view of this, many studies focus on analyzing morphological and, mainly, molecular patterns of breast cancer, with the purpose of grouping these tumors into classes or entities to assist in clinical management, in the elaboration of epidemiological and functional studies, and in the performance of clinical trials. The most common special histological types of breast cancer include: medullary carcinoma, metaplastic carcinoma, apocrine carcinoma, mucinous carcinoma, cribriform carcinoma, tubular carcinoma, neuroendocrine carcinoma, classic lobular carcinoma, and pleomorphic lobular carcinoma, in addition to the non-specific type of invasive ductal carcinoma, which constitutes the majority of newly diagnosed cases. As to their molecular aspect, intrinsic subtypes were identified based on global studies of gene expression profiles. Today, four molecular subgroups are widely reproduced and well established in the clinical routine, namely: Luminal A, Luminal B, HER2 +, and Triple Negative. Thus, the present article aims to briefly address the histological and molecular classification of breast cancer.

KEYWORDS: breast cancer; classification; neoplasms.

\section{INTRODUCTION}

Cancer has become one of the main causes of morbidity and mortality on a global scale in recent decades, as a result largely due to demographic, economic and epidemiological transitions ${ }^{1,2}$. Among the female population, breast cancer is the most common malignancy in the world (154 out of 185 countries), except in West Africa, where cervical cancer prevailed. In 2018, a total of 2.1 million women were diagnosed with breast cancer, approximately one new case diagnosed every 18 seconds. In addition, breast cancer also represents the highest cancer mortality rates in women across the globe (103 out of 185 countries), with roughly 626,600 deaths due to the disease, with the main exceptions being the countries of Northern Europe, South America North and Sub-Saharan Africa, where the main causes of death were due to cervical and/or lung cancer ${ }^{2-4}$.

In Brazil, according to the latest publication for the 2020-2021 biennium, produced by the National Cancer Institute (INCA), approximately 66,280 new cases of breast cancer annually, with an estimated risk of 61.61 cases per 100 thousand women. Without considering non-melanoma skin cancer, this type of malignancy is the second most incident in the general population and the most incident among the female population in Brazil, representing $29.7 \%$ of all cancer cases in this population, surpassing the world average, estimated at $24.2 \%^{5}$. It is known by the scientific community that the morphological and molecular aspects of breast cancer have been thoroughly explored and that these studies sought further clarification of the tumor heterogeneity of breast cancer. Therefore, this article aims to briefly address the current status of the histological and molecular classification of breast cancer. For that to be accomplished, articles were searched in the PubMed database without language restrictions. The search terms "breast cancer" were used in combination with specific terms that cover the different histological and molecular subtypes, as appropriate. We selected publications widely over

${ }^{1}$ Faculty of Medicine, Universidade de São Paulo - São Paulo (SP), Brazil.

2ProNutrir Nutritional Support and Chemotherapy - Fortaleza (CE), Brazil.

*Corresponding author: renanfarmaceutico@outlook.com

Conflict of interests: nothing to declare.

Received on: 04/29/2019. Accepted on: 06/26/2020. 
the last five years, and did not exclude older, commonly referenced and highly regarded publications. We also searched the reference lists of articles identified by this search strategy and selected those that we deemed relevant.

\section{HISTOLOGICAL CLASSIFICATION}

For the morphological study of breast cancer, we must understand whether the tumor is limited to the epithelial component of the breast or has invaded the surrounding stroma, and whether this tumor appeared in the mammary ducts or lobes ${ }^{6}$. However, in histopathological practice, cell type characteristics, number of cells, type and location of secretion, immunohistochemical profile and architectural characteristics determine if the tumor is ductal or lobular, in addition to its sub-classifications, rather than its precise location in the mammary tissue ${ }^{7,8}$. About $50 \%$ to $80 \%$ of newly diagnosed breast cancer cases are called invasive ductal carcinoma (IDC); the rest of the cases are

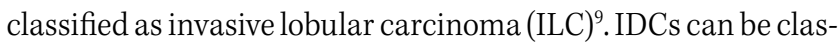
sified as "no specific type" because these tumors do not present sufficient morphological characteristics to be determined as a characteristic histological type; they can also be recognized as a "special type" if they present sufficient distinctive characteristics, and particular cellular and molecular behavior ${ }^{9,10}$. The most common special types of breast cancer include: medullary carcinoma, metaplastic carcinoma, apocrine carcinoma, mucinous carcinoma, cribriform carcinoma, tubular carcinoma, neuroendocrine carcinoma, classic lobular carcinoma, and pleomorphic lobular carcinoma ${ }^{10}$.

\section{Invasive ductal carcinoma no specific type (IDC-NST)}

The histological subtype IDC-NST is the most common, constituting about $40 \%$ to $75 \%$ of all invasive breast carcinomas. Usually, it has a wide scope of morphological variation and clinical behavior $^{10}$. Tumor cells are pleomorphic, with protruding nucleoli and numerous mitoses. Areas of necrosis and calcifications can be detected in more than half of the cases ${ }^{7,10}$.

\section{Medullary carcinoma}

Special subtype of invasive breast carcinoma, responsible for approximately $5 \%$ of all cases, and associated with better clinical results and lower rates of involvement in axillary lymph nodes $^{11}$. It usually affects patients between 30 and 40 years old and is often associated with mutations in the BRCAl germline (Breast cancer gene 1) $)^{10}$. Microscopically, it is a well-circumscribed carcinoma, composed of large and pleomorphic tumor cells, with a syncytial growth pattern, frequent mitotic figures and prominent lymphoplasmacytic infiltrate (Figure 1A). Other commonly seen features include spindle cell metaplasia and giant tumor cells $\mathrm{s}^{12,13}$.

\section{Metaplastic carcinoma}

This histological subtype is characterized by the dominant component of metaplastic differentiation, representing approximately $1 \%$ of all cases and affecting women, mainly in post-menopause ${ }^{14}$. This group of tumors shows aggressive biological behavior and an often lymph node involvement ${ }^{15}$. Morphologically, it is a poorly differentiated heterogeneous tumor that contains ductal carcinoma cells mixed with other histological elements, such as squamous cells, spindle cells or other mesenchymal differentiation, such as chondroid cells, bone cells, and myoepithelial cells (Figure 1B) $)^{12,15}$.

\section{Apocrine carcinoma}

It constitutes about $1 \%$ to $4 \%$ of all cases, with prominent apocrine differentiation comprising at least $90 \%$ of tumor cells ${ }^{7}$. This subtype is generally of high histological grade, with poor prognosis and affects a wide age group, but it is more commonly seen in postmenopausal women ${ }^{16}$. Microscopically, tumor cells are large, with an abundant granular eosinophilic cytoplasm, positive for PAS (Periodic acid-reactive Schiff) staining and prominent nucleoli; in addition, bizarre tumor cells with multilobulated nuclei can also be observed (Figure 1C) ${ }^{12,17}$.

\section{Mucinous carcinoma}

It is a special subtype of breast cancer, also known as colloid, gelatinous, mucous and mucoid carcinoma, responsible for $2 \%$ of all newly diagnosed cases ${ }^{11}$. This subtype has been associated with a favorable prognosis and often affects women over 60 years of age ${ }^{18}$. Morphologically, these tumors have abundant amounts of extracellular mucin, surrounding small clusters of tumor cells with different growth patterns and with mild nuclear atypia (Figure 1D) ${ }^{12,19}$.

\section{Cribriform carcinoma}

Special subtype associated to a good prognosis, generally affecting patients who are approximately 50 years old and constituting about $1 \%$ to $3.5 \%$ of all breast cancer cases ${ }^{6}$. Cribriform carcinoma has almost no evidence of regional or distant metastasis ${ }^{7}$. Microscopically, this subtype presents islands of uniform tumor cells, with low-grade atypia, cribriform appearance in $90 \%$ of the tumor and often associated with DCIS (Ductal carcinoma in situ) without well-defined stromal invasion (Figure 1E) ${ }^{20}$.

\section{Tubular carcinoma}

Well-differentiated subtype, occurring in women between 50 and 60 years of age and constituting about $2 \%$ of all newly diagnosed cases ${ }^{11}$. Most tubular carcinomas are associated to a wide range of potentially premalignant proliferative lesions ${ }^{21}$. This subtype is characterized by the proliferation of prominent tubules (>90\%), which can be angled, oval or elongated, with a 
disorganized disposition and open lumen covered by a single layer of epithelium, usually without presentation of necrosis and mitosis (Figure $1 \mathrm{~F})^{12,22}$.

\section{Neuroendocrine carcinoma}

It constitutes about $0.5 \%$ to $5 \%$ of all cases of breast cancer and commonly occurs in older ages ${ }^{10}$. This type of tumor has characteristics similar to neuroendocrine tumors of the gastrointestinal tract and lung, consistently expressing the markers chromogranin A and synaptophysin in more than $50 \%$ of neoplastic cells ${ }^{23}$. Morphologically, there is an infiltrative growth pattern with solid aggregates of tumor cells arranged in alveolar, trabecular or rosette patterns, and peripheral palisades can also be observed ${ }^{12}$. Neoplastic cells can be of different sizes and generally have fine eosinophilic granular cytoplasm (Figure 1G) ${ }^{24}$.

\section{Invasive lobular carcinoma}

It is the second largest biologically distinct carcinoma, representing about $5 \%$ to $15 \%$ of all newly diagnosed cases and generally affecting women of advanced age ${ }^{11}$. The classic form of the ILC is characterized by the presence of small tumor cells with little atypia, uniformly distributed throughout the stroma in a concentric pattern (Figure $1 \mathrm{H})^{10}$. Among pleomorphic ILC, tumor cells have a hyperchromatic and eccentric nucleus, prominent mitoses and apocrine. Histiocytic or signet ring cells can be observed (Figure 1I) and they are more likely to have TP53 mutations (Tumor protein 53$)^{25}$.

\section{MOLECULAR CLASSIFICATION}

We now know that breast cancer represents a biologically and phenotypically heterogeneous collection of diseases with different clinical and treatment response behaviors ${ }^{26}$. In this era of
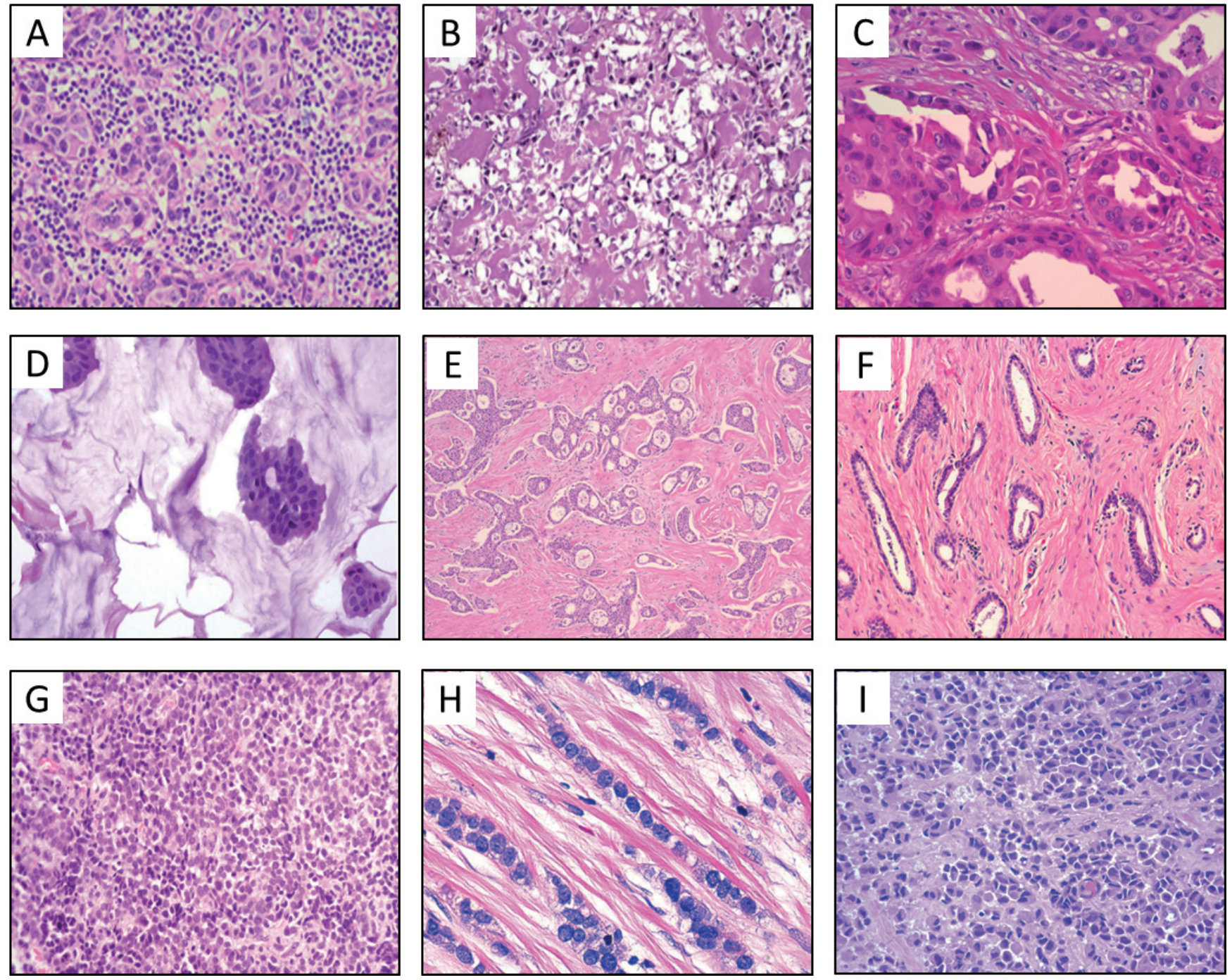

Figure 1. Morphological variants representative of the main subtypes of invasive breast carcinomas. (A) medullary carcinoma; (B) metaplastic carcinoma; (C) apocrine carcinoma; (D) mucinous carcinoma; (E) cribriform carcinoma; (F) tubular carcinoma; (G) neuroendocrine carcinoma; $(\mathrm{H})$ classic lobular carcinoma; and (I) pleomorphic lobular carcinoma. 
modern medicine, only the morphological classification (nuclear grade, tubular grade, mitotic index, histological grade, and architectural characteristics) and the clinical pathological parameters (tumor size, lymph node involvement, metastasis), are insufficient to predict the real behavior of breast tumor pathophysiology $y^{10,27}$. Thus, many studies focus on analyzing the molecular patterns of breast cancer in order to group these tumors into classes or entities to assist in clinical management, in the preparation of epidemiological and functional studies and in the performance of clinical trials ${ }^{28-34}$.

The pioneering work by Perou, Sorlie and colleagues at the beginning of this millennium classified breast cancer molecularly into distinct subgroups, based on similarities in gene expression profiles, using the cDNA microarray technique ${ }^{31,33,34}$. Thus, these studies demonstrated that there are breast cancer subtypes with differences in gene expression patterns, reflecting the individual phenotype, disease prognosis and systemic treatment planning ${ }^{35}$. Based on comprehensive gene expression profile studies, four clinically relevant molecular subtypes were revealed: Luminal A, Luminal B, enriched HER2 (HER2+), and Triple Negative (TN) (36). The groups of genes responsible mainly for the segregation of the molecular subtypes of breast cancer are genes related to the expression of estrogen receptors (ER), progesterone receptors (PR), HER2 (Human epidermal growth factor receptor 2), and cell proliferation regulator (Ki-67) ${ }^{1}$. The Immunohistochemical (IHC) panel with these four biomarkers (ER/PR/HER2/Ki-67) has been considered efficient and significant in the stratification of these molecular entities ${ }^{6,35}$. However, the growing need to improve risk stratification and accurate prognosis determination, in addition to an accurate understanding of tumor biology, led to the development of many multigenic assays, such as Oncotype $D X$, Prosigna PAM50 and Mammaprint ${ }^{36-39}$. The signature of 70 genes (Mammaprint) and of 21 genes (Oncotype DX) are being used in patients with ER+ disease at an early clinical stage to distinguish women who may have the greatest risk of recurrence and who would benefit from adjuvant chemotherapy ${ }^{40,41}$. The PAM50 trial (Prosigna) is a classifier for breast cancer subtypes. It also assesses a patient's risk for distant recurrence of the disease and the likelihood of efficacy of neoadjuvant chemotherapy ${ }^{40,41}$.

Molecular subtyping changed our view of breast cancer, with the possibility of stratifying this neoplasm in different entities that require specific treatments and different monitoring strategies, in addition to a better understanding of the pathophysiological pattern and clinical prognosis. Next, we briefly present the different molecular subtypes of breast cancer.

\section{Luminal A}

This molecular subtype is the most common and comprises approximately half of newly diagnosed breast cancer cases? According to the last update of St. Gallen in 2013, the immunohistochemical profile of this subtype was defined as: $\mathrm{ER}+(\geq 1 \%)$, high expression of PR $(\geq 20 \%)$, HER2- $(\leq 10 \%)$, and low levels of Ki-67 $(<14 \%)^{42}$. In addition, these tumors have characteristics of luminal epithelial cells of the breast, such as the high expression of cytokeratin's $7 / 8 / 18 / 19^{43}$. They include a wide range of low histological grade variants, such as IDC-NST, tubular, cribriform, mucinous, and classic ILC ${ }^{6,43}$. This subtype has been associated with a highly favorable prognosis, with a more indolent clinical course, and generally shows less lymph node involvement ${ }^{44}$. Nonetheless, due to the positive status of hormone receptors, patients benefit from endocrine therapies, either with selective estrogen receptor modulators (tamoxifen) or with aromatase inhibitors (anastrozole) (Table 1) $)^{45}$.

\section{Luminal $B$}

Responsible for approximately $20 \%$ to $30 \%$ of invasive breast cancer cases $^{26}$. This subtype can be categorized immunophenotypically into Luminal B (HER-): ER+ ( $\geq 1 \%$ ), PR- or $<20 \%$, HER2- $(\leq 10 \%)$ and high levels of Ki-67 $(\geq 20 \%)$; or Luminal B (HER2+): ER+ $(\geq 1 \%)$, HER $2+(>10 \%)$ and any level of PR and

Table 1. Classification of molecular subtypes of breast cancer and therapies.

\begin{tabular}{|c|c|c|c|c|c|}
\hline \multirow{2}{*}{ Molecular Subtypes } & \multirow{2}{*}{ Luminal A } & \multicolumn{2}{|c|}{ Luminal B } & \multirow{2}{*}{ HER 2+ } & \multirow{2}{*}{ TN } \\
\hline & & (HER2-) & (HER2+) & & \\
\hline Biomarkers & $\begin{array}{c}\text { ER+ } \\
\text { PR+ } \\
\text { HER2- } \\
\text { Ki67low }\end{array}$ & $\begin{array}{c}\text { ER+ } \\
\text { PR- } \\
\text { HER2- } \\
\text { Ki67high }\end{array}$ & $\begin{array}{c}\text { ER+ } \\
\text { PR-/+ } \\
\text { HER2+ } \\
\text { Ki67low/high }\end{array}$ & $\begin{array}{c}\text { ER- } \\
\text { PR- } \\
\text { HER2+ } \\
\text { Ki67high }\end{array}$ & $\begin{array}{c}\text { ER- } \\
\text { PR- } \\
\text { HER2- } \\
\text { Ki67high }\end{array}$ \\
\hline Frequency of Cases (\%) & $40-50$ & \multicolumn{2}{|c|}{$20-30$} & $15-20$ & $10-20$ \\
\hline Histological Grade & $\begin{array}{l}\text { Well Differentiated } \\
\text { (Grade I) }\end{array}$ & \multicolumn{2}{|c|}{ Moderately Differentiated (Grade II) } & $\begin{array}{l}\text { Little Differentiated } \\
\text { (Grade III) }\end{array}$ & $\begin{array}{l}\text { Little Differentiated } \\
\text { (Grade III) }\end{array}$ \\
\hline Prognosis & Good & \multicolumn{2}{|c|}{ Intermediate } & Poor & Poor \\
\hline Response to Therapies & Endocrine & $\begin{array}{c}\text { Endocrine } \\
\text { Chemotherapy }\end{array}$ & $\begin{array}{c}\text { Endocrine } \\
\text { Chemotherapy } \\
\text { Target Therapy }\end{array}$ & $\begin{array}{l}\text { Target Therapy } \\
\text { Chemotherapy }\end{array}$ & $\begin{array}{l}\text { Chemotherapy } \\
\text { PARP Inhibitors }\end{array}$ \\
\hline
\end{tabular}

ER: estrogen receptor; PR: progesterone receptor; HER2: human epidermal growth factor receptor 2. 
Ki- $67^{42,46}$. The expression of low molecular weight cytokeratin's from luminal epithelial cells is a rule ${ }^{26}$. This molecular entity generally presents a moderate histological grade, including most of the IDC-NST and associated with an intermediate prognosis, with greater likelihood of locoregional recurrence when compared to Luminal $\mathrm{A}^{44,47}$. Luminal B subtype is understood as the most aggressive form of ER+ breast cancer cases and often does not show benefits for hormone therapy (Table 1) ${ }^{27}$ (EXCLUDED). Luminal B subtype is understood as the most aggressive form of hormone-dependent breast cancer cases, requiring additional treatments to hormonal therapy, such as chemotherapy (when HER $2+/$-) or targeted target therapy (when HER 2 +) (Table 1) ${ }^{27}$. The main difference in the molecular aspect between the two luminous subgroups is the increased expression of genes related to cell proliferation, such as NSEP1 (Nuclease sensitive element binding protein 1) and cyclin E1 (CCNE1), in addition to the activation of certain alternative pathways of growth factors, such as PI3K (Phosphatidyllinositol 3-Kinase) and Src (Proto-oncogene sarcoma) in Luminal B breast tumors ${ }^{36}$.

\section{HER2+}

It represents $15 \%$ to $20 \%$ of newly diagnosed breast cancer cases ${ }^{48}$. This subtype is characterized by a high expression of HER2 (> 10\%), negativity for ER $(<1 \%)$ and PR $(<20 \%)$, and high expression of Ki-67 $(>20 \%)^{42}$. In addition to the immunophenotypic characterization routinely used to assess the status of HER2 in breast cancer, the FISH (Fluorescence in situ hybridization) technique has also been employed to assess gene amplification ${ }^{49}$. According to the latest clinical practice guidelines provided by the American Society of Clinical Oncology (ASCO), if the IHC result shows complete staining of the cell membrane with strong marking, the diagnosis is positive for HER2; if staining of low to moderate intensity is observed, it will be necessary to use the FISH assay with an additional observer to confirm positivity, and, finally, in cases with negative marking the complete weak staining of the membrane, the diagnosis can be confirmed as negative for HER $2^{50}$. HER2 overexpression occurs almost exclusively in the ILC pleomorphic variant ${ }^{27}$. The amplification of the gene and the elevated expression of the HER2 protein has been related to tumors of greater histological grade, high proliferative index and propensities to metastasis, leading to short disease-free survival and worse prognosis ${ }^{26}$. However, these tumors may respond well to drugs that block HER2 activity, especially humanized monoclonal antibodies (Trastuzumab) and molecular receptor tyrosine kinase inhibitors (Lapatinib) ${ }^{35,51}$.

\section{Triple negative}

This class of tumors constitutes from $10 \%$ to $20 \%$ of all breast cancer cases ${ }^{35}$. This subtype is characterized by the lack of expression of the hormone receptors ER $(<1 \%)$ and PR $(<20 \%)$ and the oncoprotein HER2 $(\leq 10 \%)$; moreover, they are highly proliferative tumors, according to the Ki-67 index $(>30 \%)^{42}$. Most TN tumors manifest as the IDC-NST histological type. However, they also include variants of medullary, metaplastic and apocrine carcinomas ${ }^{26}$. These tumors are generally more prevalent in patients with BRCA1 mutations and young women, with a higher histological grade, risk of loco-regional recurrence, contralateral disease and systemic relapse ${ }^{52}$. Many gene expression profile studies have been carried out to better understand the heterogeneity of this particularly aggressive form of breast cancer. Thus, TN tumors can be further divided into seven other distinct entities, including two basal-like types (BL1 and BL2), with a basal pattern of gene expression, but showing differences in the immune response; one of the luminal androgen receptor type (LAR), which presents differential expression of genes involved in androgen metabolism; one of the immunomodulatory type (IM), which presents important changes in the expression of genes involved in immunological signaling pathways; one of the claudin-low types (CL), characterized by the low expression of cellular junction proteins (claudins 3, 4 and 7, in addition to E-cadherin); and two of the mesenchymal type, namely, mesenchymal itself (M) and mesenchymal stem-like (MSL), both with positive regulation of the signaling pathways involved in EMT (epithelial mesenchymal transition), but differing in the signaling of genes associated to stem cells and angiogenic factors ${ }^{29,30,32,53}$. Despite its simple definition, this subtype has been a challenge for the clinic, due to its morphological, molecular and clinical heterogeneity and the lack of targeted therapies ${ }^{54}$. Non-surgical treatment of the TN subtype has been limited to platinum-based chemotherapy and PARP (Poly ADP-ribose polymerase) inhibitors for patients with BRCA1 and 2 mutations ${ }^{27,55}$.

Although great advances have occurred in high-performance molecular techniques and bioinformatics during the last decades, which allowed refinement in the stratification of breast cancer, molecular tests are still evolving, arising important questions:

- How many subtypes of this malignant neoplasm are there?

- Which molecular classification system is more robust?

- Are the classifications able to illustrate intratumoral heterogeneity and clonal evolution?

- How should we interpret breast cancer subtypes?;

- Is it possible for different classification schemes in clinical practice to exist ${ }^{56,57}$ ?

These questions will be answered over the next years.

The accumulation of knowledge around cellular and molecular biology, clinical behavior and therapeutic response, added to the emergence of new drugs and new treatment modalities, undoubtedly brought a greater understanding and quality in the management of breast cancer ${ }^{36}$. All the improvements obtained so far are a great achievement for humanity and occurred thanks to the contributions of many researchers around the world ${ }^{1,58}$. 


\section{CONCLUSION}

Despite great advances in the stratification of breast cancer subtypes, the greatest obstacle currently found in clinical oncology is the complete understanding of intertumoral heterogeneity (illustrated by tumor size, regional lymph node status, distant metastases and differences in survival), especially the intratumoral heterogeneity (illustrated by histological and biomolecular variability, chromosomal, genomic, metabolic and epigenetic changes, in addition to cellular plasticity and the tumor microenvironment), which impacts the adversity of diagnosis and accurate prognosis, and weakening strategies in personalized medicine. In addition, resistance to multiple drugs (RMD) is considered the biggest obstacle in the systemic treatment of breast cancer, making the disease often uncontrollable and leading to high mortality rates. The mechanisms underlying drug resistance are still poorly understood. However, anti-apoptotic resistance, ATP-dependent drug efflux pumps, changes in drug targets, epigenetic changes, EMT and miRNAs make up important factors for failures in anti-cancer therapies. In this context, hundreds of other candidates for biomarkers have been investigated and studied for potential implications for diagnosis, prognosis, drug targets and predictor of therapeutic response, "justifying regular reviews".

\section{AUTHORS' CONTRIBUTION}

R.G.N.: Conceptualization, investigation, methodology, project administration, supervision, validation, visualization, writing - review \& editing.

K.M.O.: Formal analysis, investigation, writing - review \& editing.

\section{REFERENCES}

1. Lukong KE. Understanding breast cancer - The long and winding road. BBA Clin. 2017;7(1):64-77. http://dx.doi. org/10.1016/j.bbacli.2017.01.001

2. Bray F, Ferlay J, Soerjomataram I, Siegel RL, Torre LA, Jernal A. Global Cancer Statistics 2018: GLOBOCAN Estimates of Incidence and Mortality Worldwide for 36 Cancers in 185 Countries. CA Cancer J Clin. 2018;68(6):394-424. https://doi. org/10.3322/caac. 21492

3. Ferlay J, Colombet M, Soerjomataram I, Mathers C, Parkin $\mathrm{DM}$, Piñeros $\mathrm{M}$, et al. Estimating the global cancer incidence and mortality in 2018: GLOBOCAN sources and methods. Int J Cancer. 2019;144(8):1941-53. https://doi.org/10.1002/ijc.31937

4. Torre LA, Islami F, Siegel RL, Ward EM, Jemal A. Global cancer in women: Burden and trends. Cancer Epidemiol Biomarkers Prev. 2017;26(4):444-57. https://doi.org/10.1158/1055-9965.epi-16-0858

5. Brasil. Ministério da Saúde. Instituto Nacional de Câncer José Alencar Gomes da Silva. Estimativa 2020: Incidência de Câncer no Brasil. Brasil: INCA; 2019. 120 p.

6. Vuong D, Simpson PT, Green B, Cummings MC, Lakhani SR. Molecular classification of breast cancer. Virchows Arch. 2014;465(1):1-14. https://doi.org/10.1007/s00428-014-1593-7

7. Makki J. Diversity of breast carcinoma: Histological subtypes and clinical relevance. Clin Med Insights Pathol. 2015;8(1):2331. https://dx.doi.org/10.4137\%2FCPath.S31563

8. Nounou MI, ElAmrawy F, Ahmed N, Abdelraouf K, Goda S, Syed-Sha-Qhattal H. Breast cancer: Conventional diagnosis and treatment modalities and recent patents and technologies. Breast Cancer Basic Clin Res. 2015;9(Suppl. 2):17-34. https:// dx.doi.org/10.4137\%2FBCBCR.S29420

9. Henry NL, Cannon-Albright L. Breast Cancer Histologic Subtypes Show Excess Familial Clustering. Wiley Cancer. 2019;125(18):3131-8. https://doi.org/10.1002/cncr.32198

10. Masood S. Breast Cancer Subtypes: Morphologic and Biologic Characterization. Womens Health. 2016;12(1):103-19. https:// doi.org/10.2217\%2Fwhe.15.99
11. Akram M, Iqbal M, Daniyal M, Khan AU. Awareness and current knowledge of breast cancer. Biol Res. 2017;50(1):33. https://doi.org/10.1186/s40659-017-0140-9

12. Provenzano E, Ulaner GA, Chin SF. Molecular Classification of Breast Cancer. PET Clin. 2018;13(3):325-38. https://doi. org/10.1016/j.cpet.2018.02.004

13. Zangouri V, Akrami M, Tahmasebi S, Talei A, Hesarooeih AG. Medullary breast carcinoma and invasive ductal carcinoma: A review study. Iran J Med Sci. 2018;43(4):365-71. https://doi. org/10.21859/mci-supp-100

14. Sinn HP, Kreipe H. A brief overview of the WHO classification of breast tumors, 4th edition, focusing on issues and updates from the 3rd edition. Breast Care. 2013;8(2):149-54. https:// dx.doi.org/10.1159\%2F000350774

15. Schwartz TL, Mogal H, Papageorgiou C, Veerapong J, Hsueh EC. Metaplastic breast cancer: Histologic characteristics, prognostic factors and systemic treatment strategies. Exp Hematol Oncol. 2013;2(1):31. https://dx.doi. org/10.1186\%2F2162-3619-2-31

16. Vranic S, Schmitt F, Sapino A, Costa JL, Reddy S, Castro M, et al. Apocrine carcinoma of the breast: A comprehensive review. Histol Histopathol. 2013;28(11):1393-409. https://doi. org $/ 10.14670 /$ hh-28.1393

17. Vranic S, Feldman R, Gatalica Z. Apocrine carcinoma of the breast: A brief update on the molecular features and targetable biomarkers. Bosn J Basic Med Sci. 2017;17(1):9-11. https://doi. org/10.17305/bjbms.2016.1811

18. Marrazzo E, Frusone F, Milana F, Sagona A, Gatzemeier W, Barbieri E, et al. Mucinous breast cancer: A narrative review of the literature and a retrospective tertiary single-centre analysis. Breast. 2020;49(1):87-92. https://doi.org/10.1016/j. breast.2019.11.002

19. Dumitru A, Procop A, Iliesiu A, Tampa M, Mitrache L, Costache M, et al. Mucinous Breast Cancer: a Review Study of 5 Year Experience from a Hospital-Based Series of Cases. Maedica (Buchar). 2015;10(1):14-8 
20. Cong Y, Qiao G, Zou H, Lin J, Wang X, Li X, et al. Invasive cribriform carcinoma of the breast: A report of nine cases and a review of the literature. Oncol Lett. 2015;9(4):1753-8. https:// dx.doi.org/10.3892\%2Fol.2015.2972

21. Zhang WW, Wu SG, Ling YH, Sun JY, Long ZQ, Hua X, et al. Clinicopathologic characteristics and clinical outcomes of pure type and mixed type of tubular carcinoma of the breast: A singleinstitution cohort study. Cancer Manag Res. 2018;10(1):450915. https://dx.doi.org/10.2147\%2FCMAR.S177046

22. Fritz P, Bendrat K, Sonnenberg M, Trautmann C, Ott G, Heidemann E, et al. Tubular breast cancer. A retrospective study. Anticancer Res. 2014;34(7):3647-56.

23. Jur囚i冈 P, Kruslin B, Gatalica Z, Sanati S, Vranic S. Breast carcinoma with neuroendocrine features: a brief review. Endocr Oncol Metab. 2016;2(2):138-45. https://dx.doi. org/10.21040/eom/2016.2.2.6

24. Li Y, Du F, Zhu W, Xu B. Neuroendocrine carcinoma of the breast: A review of 126 cases in China. Chin J Cancer. 2017;36(1):45. https://dx.doi.org/10.1186\%2Fs40880-017-0211-x

25. Thomas M, Kelly ED, Abraham J, Kruse M. Invasive lobular breast cancer: A review of pathogenesis, diagnosis, management, and future directions of early stage disease. Semin Oncol. 2019;46(2):121-32. https://doi.org/10.1053/j. seminoncol.2019.03.002

26. Feng Y, Spezia M, Huang S, Yuan C, Zeng Z, Zhang L, et al. Breast cancer development and progression: Risk factors, cancer stem cells, signaling pathways, genomics, and molecular pathogenesis. Genes Dis. 2018;5(2):77-106. https:// doi.org/10.1016/j.gendis.2018.05.001

27. Fragomeni SM, Sciallis A, Jeruss JS. Molecular Subtypes and Local-Regional Control of Breast Cancer. Surg Oncol Clin N Am. 2018;27(1):95-120. https://dx.doi.org/10.1016\%2Fj.soc.2017.08.005

28. Burstein MD, Tsimelzon A, Poage GM, Covington KR, Fuqua SAW, Savage MI, et al. Comprehensive Genomic Analysis Identifies Novel Subtypes and Targets of Triple-negative Breast Cancer. Clin Cancer Res. 2015;21(7):1688-98. https://doi. org/10.1158/1078-0432.ccr-14-0432

29. Lehmann BD, Bauer JA, Chen X, Sanders ME, Chakravarthy $\mathrm{AB}$, Shyr $\mathrm{Y}$, et al. Identification of human triple-negative breast cancer subtypes and preclinical models for selection of targeted therapies. J Clin Invest. 2011;121(7):2750-67. https:// dx.doi.org/10.1172\%2FJCI45014

30. Lehmann BD, Jovanovic B, Chen X, Estrada M V, Johnson $\mathrm{N}$, Shyr Y, et al. Refinement of Triple-Negative Breast Cancer Molecular Subtypes: Implications for Neoadjuvant Chemotherapy Selection. PLoS One. 2016;11(6):e0157368. https://doi.org/10.1371/journal.pone.0157368

31. Perou CM, Sorlie T, Eisen MB, van de Rijn M, Jeffrey SS, Rees CA, et al. Molecular portraits of human breast tumours. Nature. 2000;406(6797):747-52. https://doi.org/10.1038/35021093

32. Prat A, Perou CM. Deconstructing the molecular portraits of breast cancer. Mol Oncol. 2011;5(1):5-23. https://dx.doi. org/10.1016\%2Fj.molonc.2010.11.003

33. Sorlie T, Perou CM, Tibshirani R, Aas T, Geisler S, Johnsen $\mathrm{H}$, et al. Gene expression patterns of breast carcinomas distinguish tumor subclasses with clinical implications.
Proc Natl Acad Sci U S A. 2001;98(19):10869-74. https://doi. org/10.1073/pnas.191367098

34. Sorlie T, Tibshirani R, Parker J, Hastie T, Marron JS, Nobel A, et al. Repeated observation of breast tumor subtypes in independent gene expression data sets. Proc Natl Acad Sci. 2003;100(14):8418-23. https://doi.org/10.1073/pnas.0932692100

35. Tsang JYS, Tse GM. Molecular Classification of Breast Cancer. Adv Anat Pathol. 2020;27(1):27-35. https://doi.org/10.1097/ pap.0000000000000232

36. Harbeck N, Penault-Llorca F, Cortes J, Gnant M, Houssami N, Poortmans P, et al. Breast cancer. Nat Rev Dis Prim. 2019;5(1):66. https://doi.org/10.1038/s41572-019-0111-2

37. Parker JS, Mullins M, Cheung MCU, Leung S, Voduc D, Vickery $\mathrm{T}$, et al. Supervised risk predictor of breast cancer based on intrinsic subtypes. J Clin Oncol. 2009;27(8):1160-7. https:// dx.doi.org/10.1200\%2FJCO.2008.18.1370

38. Paik S, Shak S, Tang G, Kim C, Baker J, Cronin M, et al. A multigene assay to predict recurrence of tamoxifen-treated, node-negative breast cancer. N Engl J Med. 2004;351(27):281726. https://doi.org/10.1056/nejmoa041588

39. Vijver MJV, He Y, Veer L, Dai H, Hart AAM, Voskuil DW, et al. A gene-expression signature as a predictor of survival in breast cancer. N Engl J Med. 2002;347(25):1999-2009. https://doi. org/10.1056/nejmoa021967

40. Huang S, Murphy L, Xu W. Genes and functions from breast cancer signatures. BMC Cancer. 2018;18(1):473. https://doi. org/10.1186/s12885-018-4388-4

41. Vieira AF, Schmitt F. An update on breast cancer multigene prognostic tests-emergent clinical biomarkers. Front Med. 2018;5(1):248. https://dx.doi.org/10.3389\%2Ffmed.2018.00248

42. Goldhirsch A, Winer EP, Coates AS, Gelber RD, PiccartGebhart M, Thürlimann B, et al. Personalizing the treatment of women with early breast cancer: Highlights of the st gallen international expert consensus on the primary therapy of early breast Cancer 2013. Ann Oncol. 2013;24(9):2206-23. https:// dx.doi.org/10.1093\%2Fannonc\%2Fmdt303

43. Gao JJ, Swain SM. Luminal A Breast Cancer and Molecular Assays: A Review. Oncologist. 2018;23(5):556-65. https:// dx.doi.org/10.1634\%2Ftheoncologist.2017-0535

44. Hashmi AA, Aijaz S, Khan SM, Mahboob R, Irfan M, Zafar NI, et al. Prognostic parameters of luminal A and luminal B intrinsic breast cancer subtypes of Pakistani patients. World J Surg Oncol. 2018;16(1):1-6. https://doi.org/10.1186/s12957-017-1299-9

45. Rocca A, Farolfi A, Maltoni R, Carretta E, Melegari E, Ferrario C, et al. Efficacy of endocrine therapy in relation to progesterone receptor and Ki67 expression in advanced breast cancer. Breast Cancer Res Treat. 2015;152(1):57-65. https://doi. org/10.1007/s10549-015-3423-2

46. Cheang MCU, Chia SK, Voduc D, Gao D, Leung S, Snider J, et al. Ki67 index, HER2 status, and prognosis of patients with luminal B breast cancer. J Natl Cancer Inst. 2009;101(10):73650. https://dx.doi.org/10.1093\%2Fjnci\%2Fdjp082

47. Tsoutsou PG, Vozenin MC, Durham AD, Bourhis J. How could breast cancer molecular features contribute to locoregional treatment decision making? Crit Rev Oncol Hematol. 2017;110(1):43-8. http://dx.doi.org/10.1016/j.critrevonc.2016.12.006 
48. Cho N. Molecular subtype and imaging phenotype of breast cancer. Ultrasonography. 2016;35(4):281-8. http://dx.doi. org/10.14366/usg.16030

49. Desai NV, Torous V, Parker J, Auman JT, Rosson GB, Cruz C, et al. Intrinsic molecular subtypes of breast cancers categorized as HER2positive using an alternative chromosome 17 probe assay. Breast Cancer Res. 2018;20(1):75. https://doi.org/10.1186/s13058-018-1005-z

50. Wolff AC, Hammond MEH, Allison KH, Harvey BE, Mangu PB, Bartlett JMS, et al. Human epidermal growth factor receptor 2 testing in breast cancer: American society of clinical oncology/ college of American pathologists clinical practice guideline focused update. J Clin Oncol. 2018;36(20):2105-22. https://doi. org/10.1200/jco.2018.77.8738

51. Llombart-Cussac A, Cortés J, Paré L, Galván P, Bermejo B, Martínez N, et al. HER2-enriched subtype as a predictor of pathological complete response following trastuzumab and lapatinib without chemotherapy in early-stage HER2positive breast cancer (PAMELA): an open-label, single-group, multicentre, phase 2 trial. Lancet Oncol. 2017;18(4):545-54. http://dx.doi.org/10.1016/S1470-2045(17)30021-9

52. Kumar P, Aggarwal R. An overview of triple-negative breast cancer. Arch Gynecol Obstet. 2016;293(2):247-69. https://doi. org/10.1007/s00404-015-3859-y
53. Sabatier R, Finetti P, Guille A, Adelaide J, Chaffanet M, Viens P, et al. Claudin-low breast cancers: Clinical, pathological, molecular and prognostic characterization. Mol Cancer. 2014;13(1):228. https://doi.org/10.1186/1476-4598-13-228

54. Russnes HG, Lingjærde OC, Børresen-Dale AL, Caldas C. Breast Cancer Molecular Stratification: From Intrinsic Subtypes to Integrative Clusters. Am J Pathol. 2017;187(10):2152-62. https:// doi.org/10.1016/j.ajpath.2017.04.022

55. Yam C, Mani S, Moulder S. Targeting the Molecular Subtypes of Triple Negative Breast Cancer: Understanding the Diversity to Progress the Field. Oncologist. 2017;22(9):1086-93. https:// dx.doi.org/10.1634/theoncologist.2017-0095

56. Rakha EA, Green AR. Molecular classification of breast cancer: what the pathologist needs to know. Pathology. 2017;49(2):1119. https://doi.org/10.1016/j.pathol.2016.10.012

57. Song Q, Merajver SD, Li JZ. Cancer classification in the genomic era: five contemporary problems. Hum Genomics. 2015;9(1):27. https://doi.org/10.1186/s40246-015-0049-8

58. Ades F, Tryfonidis K, Zardavas D. The past and future of breast cancer treatment - From the papyrus to individualised treatment approaches. Ecancermedicalscience. 2017;11(1):746. https://dx.doi.org/10.3332/ecancer.2017.746 